\title{
Modified randomized response technique to detect respondent reticence
}

\author{
Dulani Samaranayake \\ Department of Community Medicine, University of Colombo, Sri Lanka \\ *Correspondence: dulani@commed.cmb.ac.lk
}

DOI: : https://doi.org/10.4038/jccpsl.v23i2.8112

Received on: 13 May 2017

Accepted on: 19 June 2017

In survey research sometimes the need arises to determine the prevalence of certain sensitive behaviours like corruption, drug use, sexual promiscuity or cheating. These behaviours due to their value-laden and sensitive nature are less likely to be expressed candidly by the respondents. Therefore, accurate estimation of the prevalence of such 'controversial' or 'sensitive' behaviour in survey research remains a challenge. Various techniques have been developed to ensure anonymity and encourage candour by minimizing the respondent's feelings of risk, of which the randomized response technique (RRT) is one of the commonly used methods.

\section{Randomized response technique}

RRT was first introduced by Warner in 1965 (1) and was subsequently developed by Greenberg and colleagues (2). Since then, the technique has been used in a variety of settings and populations to explore a wide range of sensitive behaviours such as corruption and bribery (3), illicit drug use (4-5), and dishonesty and cheating (6-7).

In RRT, when the sensitive question is posed, the participant is instructed to toss a coin and answer depending on the result of the coin toss. If the participant obtains "heads", the question is answered as "yes" irrespective of the actual answer. If they obtain "tails", the question is answered honestly. The number of 'yes' answers obtained per question is therefore made up of those who obtained 'heads' at coin toss and those who practise the sensitive behaviour out of those obtaining 'tails' at coin toss. Therefore, if the participants in the sample are truthful, the number of "yes" answers should be higher than the number of "no" answers obtained for each question. The analysis is aimed at calculating the proportion of participants who actually engage in the sensitive behaviour concerned. Therefore, for each question in the RRT, using the following notations:

$$
\begin{aligned}
& P(Y)=\text { proportion of participants answering 'Yes' } \\
& P(H)=\begin{array}{l}
\text { proportion of participants who obtain 'Heads' } \\
\text { at the coin toss }
\end{array} \\
& P(T)=\begin{array}{l}
\text { proportion of participants who obtain 'Tails' } \\
\text { at the coin toss }
\end{array} \\
& P=\quad \begin{array}{l}
\text { proportion of participants practising the } \\
\text { sensitive behaviour in the sample }
\end{array}
\end{aligned}
$$

The proportion answering “yes” $(\mathrm{P}(\mathrm{Y}))$ is made up of the proportion of participants who got "heads" at coin toss $(\mathrm{P}(\mathrm{H}))$ and the proportion of participants who answered "yes" due to actual practice of the behaviour among those who obtained 'tails' at coin toss $(P(T) * P)$.

$$
P(Y)=P(H)+P(T) * P
$$

Since the event of 'heads' and 'tails' at coin toss occur with equal probabilities of 0.5 ,

$$
\begin{aligned}
& P(H)=0.5, P(T)=0.5 \\
& P(Y)=0.5+0.5 P \\
& P=2(P(Y)-0.5) \\
& P=2 P(Y)-1
\end{aligned}
$$

The rationale behind the randomized response questions is that they would encourage respondent candour because only the respondent knows whether an answer of 'yes' reflects the sensitive activity or the coin toss. In order to RRT to be successful, the participant should be able to comprehend this logic and comply with the instructions. 


\section{Modified RRT to detect reticence}

Evidence suggests that despite the use of RRT, respondent reticence persists and affects the results of most studies employing this methodology. Synthesizing the results from a number of studies using RRT, LensveltMulders et al. (8) show that RRT is able to reduce the underreporting of sensitive acts only to $38 \%$ from $45 \%$ on average. Hence, respondent reticence does not seem to be fully overcome by the RRT. A modified version of RRT has been developed recently with the aim of identifying reticent participants.

A reticent respondent is defined as "one who gives knowingly false answers with a non-zero probability when honest answers to a specific set of survey questions could lead to the inference that the respondent might have committed a sensitive act” (9). It is assumed that the reticent respondents give untruthful answers intentionally and therefore would take possible precautions to conceal the fact that they are reticent.

The modified RRT presents survey participants with a series of ten sensitive questions (Table 1), giving the standard instruction of answering based on coin toss.

The series of ten random response questions includes three questions on less sensitive behaviours (shown in bold type). It is expected that the answers of reticent participants be driven by two forces - the need to answer the sensitive questions in negative and the need to conceal their reticence. The three less sensitive questions will provide them the opportunity to hide their reticence and answer 'yes' occasionally. Therefore, a pattern of answering 'no' to all sensitive questions and 'yes' to one or more of the less sensitive questions suggests that a participant is likely to be reticent. Such possibly reticent participants can be excluded from the analysis as well as their characteristics can be compared with the possibly candid participants.

This modified version of RRT has been successfully used to detect reticence related to corruption behaviours in different settings (9-10). Whilst the success of standard RRT depends on the participants understanding the randomization process and how it protects the truthful respondents, the modified RRT does not have this prerequisite. On the contrary, it is more likely to identify the reticent when the respondents are unaware of the protection of the randomization process. With these positive characteristics, the modified RRT seems to be a promising methodology for estimating prevalence of sensitive behaviours as well as the detection of respondent reticence with regard to them.

\section{Table 1. Statements used in a study using modified RRT to assess corruption-related behaviours of health care workers}

\begin{tabular}{llc}
\hline Statements on work practices & Response \\
\hline 1. I sometimes give priority to my relatives when I am treating hospital patients. & Yes & No \\
\hline 2. I sometimes use the telephone facility in the public hospital for my private calls. & Yes & No \\
\hline 3. I give priority to job activities that will enable me earn per-diems. & Yes & No \\
\hline 4. I sometimes go visit homes of patients of the public clinic to treat them for a fee. & Yes & No \\
\hline 5. I make more money from my supplementary sources at work than from my salary. & Yes & No \\
\hline 6. I sometimes accept money or gifts from patients to give them priority treatment. & Yes & No \\
\hline 7. I have referred patients from the public hospital to my private practice. & Yes & No \\
\hline 8. I have taken drugs and supplies from the hospital to help my patients at my private practice. & Yes & No \\
\hline 9. I sometimes have to leave some hours early from work to do my business. & Yes & No \\
\hline 10. I am sometimes one hour late to work. & Yes & No \\
\hline
\end{tabular}




\section{References}

1. Warner SL. Randomized response: A survey technique for eliminating evasive answer bias. Journal of the American Statistical Association 1965; 60(309): 63-9.

2. Greenberg BG, Abul-Ela AL, Simmons WR, Horvitz DG. The unrelated question randomized response model: theoretical framework. Journal of the American Statistical Association 1969; 64(326): 520-39.

3. Akwataghibe N, Samaranayake D, Lemiere C, Dieleman M. Assessing health workers' revenues and coping strategies in Nigeria-a mixed-methods study. BMC Health Services Research 2013; 13(1): 387.

4. Striegel H, Ulrich R, Simon P. Randomized response estimates for doping and illicit drug use in elite athletes. Drug and Alcohol Dependence 2010; 106(2): 230-2.

5. Dietz P, Striegel H, Franke AG, Lieb K, Simon P, Ulrich R. Randomized response estimates for the 12-month prevalence of cognitive-enhancing drug use in university students. Pharmacotherapy: The Journal of Human Pharmacology and Drug Therapy 2013; 33(1): 44-50. DOI: 10.1002/ phar.1166
6. Scheers NJ \& Dayton CM. Improved estimation of academic cheating behaviour using the randomized response technique. Research in Higher Education 1987; 26(1): 61-9.

7. Jacob BA \& Levitt SD. Rotten apples: An investigation of the prevalence and predictors of teacher cheating. The Quarterly Journal of Economics 2003; 118(3): 843-77.

8. Lensvelt-Mulders, Gerty JLM, Hox JJ, Peter GM, van der Heijden, Maas CJM. Meta-Analysis of randomized response research: thirty-five years of validation. Sociological Methods \& Research 2005; 33: 319-348.

9. Azfar O \& Murrell P. Identifying reticent respondents: assessing the quality of survey data on corruption and values. Economic Development and Cultural Change 2009; 57(2): 387-411.

10. Clausen B, Kraay A, Murrell P. Does respondent reticence affect the results of corruption surveys? Evidence from the World Bank enterprise survey for Nigeria. Policy Research Working Paper 5415. The World Bank, Development Research Group M, 2010. 